\title{
A study of induction of labour versus expectant management for pregnancies beyond 40 weeks a prospective comparative randomised study
}

\author{
Bhagyalakshmi Manthri ${ }^{1}$, Nina. V. Kate, ${ }^{2, *}$ \\ ${ }^{1}$ DNB Resident, ${ }^{2}$ Consultant, Dept. of Obstetrics and Gynaecology, Rajiv Gandhi Government Women \& Children Hospital, \\ Puducherry, India
}

*Corresponding Author:

Email: drninakate@gmail.com

\begin{abstract}
Introduction: Post-term pregnancy is one that extends to or beyond 42 weeks of gestation, Patients at 40 weeks can either undergo induction or can be managed expectantly. At 41 weeks of gestation the perinatal mortality rate is 9 per 1000 live births, and it continues to rise thereafter. Labour induction at 41 weeks gestation for otherwise uncomplicated singleton pregnancies reduces caesarean delivery rates without compromising perinatal outcomes.

Study Design: 200 Low risk primigravida at 40 weeks of gestation were included and randomized into two groups.

Group I=Induction group ( $\mathrm{n}=100)$ Patients were admitted at 40 weeks and were induced at $40+0$ to $40+6$ Weeks.

Patients in Group II the Expectant group which was further subdivided into 2 groups.

Group IIa=Those who went into labour or had PROM or any omnious event during the Expectant period till 41 weeks.

Group IIb=Patients who reached 41 weeks and then were induced.

Results: Expectant management till 41 weeks and then inducing labour at 41 weeks resulted in a significantly higher number of patients having vaginal delivery when compared with patients who were induced at 40weeks. The incidence of meconium stained liquor, caesarean section, non-reassuring CTG, maternal complications and neonatal morbidity was high in Group I when compared to Group II.

Conclusion: Labour induction in uncomplicated pregnancies at 41 weeks is not associated with increased rates of operative delivery, maternal and neonatal morbidity.
\end{abstract}

Keywords: Expectant management, Labor induction, Post term pregnancy.

\section{Introduction}

Pregnancy between 41 and 42 weeks is referred as prolonged pregnancy, which varies from 9.5 to $33.7 \%$ annually ${ }^{1}$ and needs to be closely monitored. An earlier induction can, potentially expose the mother to a greater risk of an operative intervention and its subsequent morbidity while delaying the induction increases the chances of fetal distress and perinatal morbidity. The incidence of prolonged pregnancy drops from $7.5 \%$ to $2.6 \%$ when gestation age is calculated by early ultrasound rather than menstrual dates. ${ }^{2}$ Since labor induction is the commonest intervention in obstetrics, WHO recommends a policy of routine induction of labor at 41 completed weeks. ${ }^{3}$ This study aims to assess the advantages and disadvantages of inducing labor in women at 40+1/ 40+6 weeks of gestation with those expectantly managed matched group of women up to 41 completed weeks of gestation and then induced. ${ }^{4}$

\section{Materials and Methods}

A prospective comparative study was undertaken in our Hospital from Jan 2015 to June 2016 after obtaining clearance from the institute's ethical committee. Women at 40 weeks of gestation satisfying the inclusion and exclusion criteria were explained the risks and benefits of the procedure and those who gave informed, written, valid consent were included in the study. They were randomised into two groups and feto- maternal surveillance was started and continued till delivery.

40 weeks of gestation (Confirmed by menstrual history and early ultra sound)
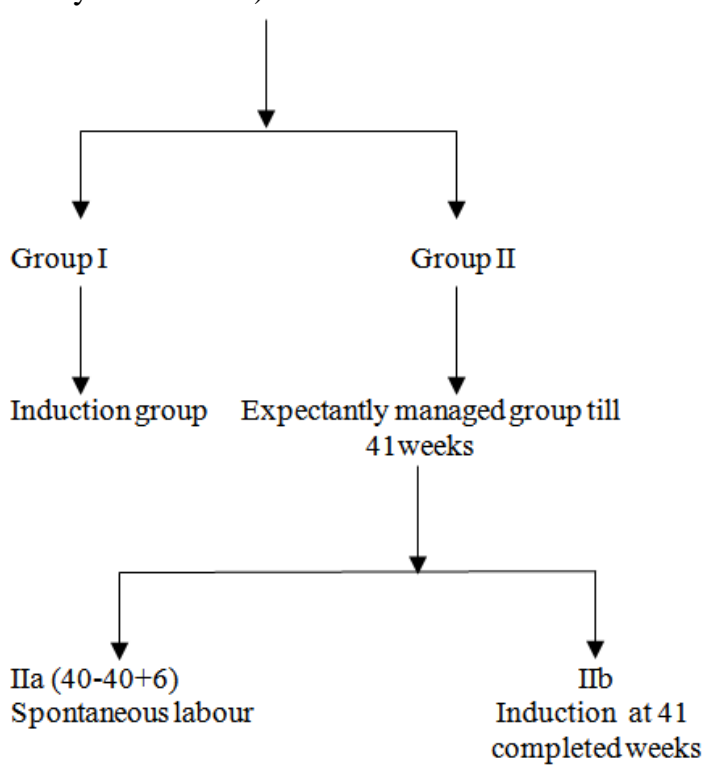

\section{Inclusion Criteria}

1. Singleton Pregnancies with cephalic presentation with 40 weeks of gestation.

2. Primigravida

3. Bishops score $<6$ 
4. Patients not in labour

5. No Premature rupture of membranes at admission

\section{Exclusion Criteria}

1. Scarred uterus like previous caesarean section, myomectomy.

2. Non cephalic presentation

3. Multifetal pregnancy

4. Intra uterine growth restriction

5. Oligohydramnios/Polyhydramnios

6. Antepartum haemorrhage

7. Co morbid conditions like pregnancy induced hypertension, diabetis mellitus, asthma

8. Anamolous babies

9. Cephalopelvic disproportion

10. Abnormal Doppler studies

The following Maternal outcomes were monitored.

1. Mode of delivery

i. Spontaneous vaginal delivery

ii. Instrumental delivery

iii. Caesarean section.

2. Hyperstimulation, Tachysystole, Fetal distress

3. Prelabour rupture of membranes (PROM)

4. Colour of liquor

5. Postpartum haemorrhage
The following fetal outcomes were monitored.

1. APGAR at 1 and 5 minutes

2. Weight of the baby

3. NICU admission (Neonatal Intensive care unit)

4. Other neonatal complications

Methods of Statistical Analysis: The data after entering in MS excel data sheet, was analyzed with SPSS software. Data was presented in the form of descriptive and inferential statistics. Descriptive statistics was expressed in frequencies, percentages, and appropriate measures of central tendency and dispersion like mean, standard deviation. As per the level of measurement of data, appropriate statistical test was applied like chi-square for categorical and t-test, ANOVA for continuous data to test the association and significant difference of mean wherever applicable, if any, in the given data.

\section{Result}

The mean period of gestational age in Induction and Expectant Group were 23.55 \pm 2.805 and $22.66 \pm 2.547$ respectively and this was not statistically significant whereas period of gestation in both groups was significant $(\mathrm{p}=0.001)$ (Table 1).

Table 1: Parameters in both groups

\begin{tabular}{|l|c|c|c|}
\hline Parameters & Induction group & Expectant group & Significance \\
\hline Age & $23.55 \pm 2.805$ & $22.66 \pm 2.547$ & NS \\
\hline Period of gestation & $40.3 \pm 2.8$ & $41.0 \pm 0.2$ & $\mathrm{P}=0.001$ \\
\hline
\end{tabular}

In Group I, all the patients were induced at $40+0$ to $40+4$ weeks of gestation where as in Group IIa, all patients went into spontaneous labor without any induction and in Group IIb, 94.2\% were induced at 41 weeks, $5.7 \%$ were induced at $>41$ weeks and this was statistically significant $(\mathrm{p}=0.001)$.

$64 \%$ of Group I patients had caesarean section, $3 \%$ had instrumental delivery and $33 \%$ had normal vaginal delivery. Where as in Group II, 65 patients delivered before 41 weeks, out of which $15.3 \%$ had caesarean section and $84.6 \%$ had normal vaginal delivery. Out of 35 patients who reached 41 weeks and were induced, $34.2 \%$ had caesarean delivery and $65.7 \%$ had normal vaginal delivery. There was statistical significance between mode of delivery in Group I and Group II $(\mathrm{p}=0.001)$ (Table 2).

Table 2: Comparison of mode of delivery in both groups

\begin{tabular}{|l|c|c|c|}
\hline Mode of delivery & Group I (100) & \multicolumn{2}{|c|}{ Group II (100) } \\
\hline SVD & $\begin{array}{c}\text { Observation till 41weeks } \\
\text { (N=65) } \\
\text { IIa }\end{array}$ & $\begin{array}{c}\text { Induction at } \\
41 \text { weeks (N=35) } \\
\text { IIb }\end{array}$ \\
\hline Vacuum-forceps & $33(33 \%)$ & $55(84.6 \%)$ & $23(65.7 \%)$ \\
\hline LSCS & $3(3 \%)$ & 0 & 0 \\
\hline Total & $64(64 \%)$ & $10(15.3 \%)$ & $12(34.2 \%)$ \\
\hline
\end{tabular}

29 patients of group I had MSL out of which 2 delivered vaginally and 27 underwent caesarean section, where as in group IIa, 6 had MSL out of which
2 delivered vaginally and 4 underwent LSCS. In group IIb, 5 had MSL and all 5 underwent LSCS $(\mathrm{P}=0.001)$ (Table 3). 
Table 3: Mode of delivery and colour of liquor

\begin{tabular}{|l|c|c|c|c|c|c|}
\hline Colour of liquor & \multicolumn{3}{|c|}{ Group I(N=100) } & \multicolumn{4}{c|}{ Group II(N=100) } \\
\hline & \multicolumn{3}{|c|}{$\begin{array}{c}\text { Observation till 41weeks } \\
\text { (N=65) IIa }\end{array}$} & $\begin{array}{c}\text { Induction at 41 weeks } \\
\text { (N=35) Ilb }\end{array}$ \\
\hline & $\begin{array}{c}\text { SVD } \\
(33)\end{array}$ & $\begin{array}{c}\text { Operative } \\
\text { delivery (67) }\end{array}$ & SVD(55) & LSCS(10) & SVD (23) & LSCS (12) \\
\hline Clear liquor & 31 & 40 & 53 & 6 & 23 & 7 \\
\hline MSL & 2 & 27 & 2 & 4 & 0 & 5 \\
\hline Total & 33 & 67 & 55 & 10 & 23 & 12 \\
\hline
\end{tabular}

In Group I only 36 had favourable bishops score. In Group IIa out of 65, 40 had Bishops score $>3$ and In Group IIb out of 35, 20 had bishops score >3. In Group I, 68 patients had reactive CTG (Cardiotocography) and remaining had Nonreactive CTG. In Group IIa out of 65patients, 57 had reactive CTG, and out of 35 in
Group IIb, 30 had reactive CTG and this was statistically significant. Only 14 patients in Group IIa had Prelabor rupture of membranes (PROM). 41 babies in Group I, 11 babies each in Group IIa and Group IIb were admitted in NICU (Table 4).

Table 4: Comparision of Bishop score, CTG, PROM and NICU admissions in both groups

\begin{tabular}{|l|c|c|c|c|}
\hline & $\begin{array}{c}\text { Group I } \\
(\mathbf{N = 1 0 0})\end{array}$ & Group IIa (N=65) & $\begin{array}{c}\text { Group IIb } \\
(\mathbf{N = 3 5})\end{array}$ & Significance (p) \\
\hline Bishop Score (>3) & 36 & 40 & 20 & 0.002 \\
\hline CTG (Reactive) & 68 & 57 & 30 & 0.02 \\
\hline PROM & 0 & 14 & 0 & 0.001 \\
\hline NICU admissions & 41 & 11 & 11 & 0.05 \\
\hline
\end{tabular}

Maternal Complications like hyperstimulation (2 patients), Uterine atony (1patient), Chorioamnionitis (1 patient) were noted in Group I. While in Group II, only one patient had hyperstimulation and no other complications were noted. When compared to Group I, Group II had less maternal complications.
The most common indication for Caesarean section in Group I and Group II was fetal distress, followed by failed induction. There was no statistical significance in relation to indication of operative interference $(\mathrm{P}=0.19)$, Birth weight $(\mathrm{P}=0.48)$, Apgar score in both groups $(\mathrm{P}=0.19)$.

Table 5: Probability of caesarean section among primigravida randomized to the induced group (Group I) and the expectant group (Group II)

\begin{tabular}{|l|c|c|}
\hline Studies & Induction Group(Group I) & Expectant Group(Group II) \\
\hline Macer et al $^{6}$ & $14.6 \%$ & $11.1 \%$ \\
\hline Hermus et al $^{10}$ & $19.4 \%$ & $16.3 \%$ \\
\hline Sanchez-Ramos et al $^{11}$ & $20.1 \%$ & $22 \%$ \\
\hline Donald et a $^{12}$ & $22 \%$ & $18 \%$ \\
\hline Ambreen et al $^{13}$ & $28.2 \%$ & $10.25 \%$ \\
\hline Hannah et al $^{14}$ & $66.3 \%$ & $33.9 \%$ \\
\hline Alexander et al $^{15}$ & $7 \%$ & $10 \%$ \\
\hline Dublin et al $^{16}$ & $19.4 \%$ & $9.9 \%$ \\
\hline Prysak et al $^{17}$ & $8.7 \%$ & $5.0 \%$ \\
\hline Augensen et al & & $30.8 \%$ \\
\hline Present Study & $82.2 \%$ & $22 \%$ \\
\hline
\end{tabular}

\section{Discussion}

Managing pregnancies expectantly till 41weeks and then inducing reduces the rate of caesarean section, intrapartum and postpartum complications and neonatal morbidity and mortality. Though recent studies show increased incidence of perinatal morbidity and mortality with increase in gestational age, there is uncertainty on the policy concerning the timing of induction for prolonged pregnancy or impending post-term pregnancy, leading to practice variation between caregivers. Managing pregnancies continuing beyond their due dates remains to be a tricky situation for the obstetrician.

The mean age of patients in Group I and Group II was $23.55 \pm 2.805$ and $22.66 \pm 2.547$ respectively which was not significant statistically. In the present study the mean period of Gestation in Induction Group and Expectant Group was $40.3 \pm 2.8$ and $41.0 \pm 0.2$ respectively (Table 1) where as in a study by Johnson et $\mathrm{al}^{5}$ and Macer et $\mathrm{al}^{6}$ the mean period of gestation in 
induction Group and expectant Group was $39.8 \pm 1.35$ and $39.5 \pm 1.15$ and $39.0 \pm 1.02$ and $39.32 \pm 0.9$ respectively.

It is well known that the successful induction of labour is related to cervical ripeness. Compared with spontaneous onset of labour, elective induction of labour in primigravida at term with an unfavourable Bishop score is associated with an increased risk of caesarean delivery. Most studies that do include the Bishop score find an increased risk of caesarean delivery when labour is induced with a low Bishop score. Present study showed that Bishops score drastically improves as the period of gestation increases. Bishops score was $<3$ in $64 \%$ of patients in Group I and $40 \%$ in Group II, whereas Bishops score was 3-6 in 36\% and 60\% of patients in Group I and Group II respectively, similar to studies conducted by Johnson et $\mathrm{al}^{5}$ and Vrouenvaets et al. ${ }^{7}$

Waiting till 41 weeks and then inducing did not have an effect on meconium staining of the liquor as seen in our study (Table 3) and as documented in studies by Cole et $\mathrm{al}^{8}$ and Heimstad et al. ${ }^{9}$

In our study, Abnormal Fetal heart rate patterns also showed significant differences $(\mathrm{p}=0.02)$ between early induction of labor to expectantly managed pregnancies (15\% vs $5 \%$ ) which indirectly increases the operative interference.

Expectantly managing pregnancies till 41 weeks allows patients to go into spontaneous labour and reduces operative deliveries whereas early induction increases the rate of operative delivery which is also substantiated in the studies as shown in Table 5.

No statistical significance was noted in Birth weight and Apgar score in both groups.

Though 41 babies in Group I and 22 babies in Group II needed NICU admissions, no major neonatal complications were noted and was not statistically significant.

\section{Conclusion}

Our study suggests that Induction of labor should be reserved for cases where maternal and perinatal benefits outweigh the risk of complications.

Elective induction of labor with an unfavourable cervix should be discouraged and waiting till 41 weeks with proper feto-maternal surveillance and then inducing improves maternal and neonatal outcome.

\section{Limitations of the study}

Since it is not a double blinded study, subjective variation in the observations noted may be present.

The period of study is short hence many outcomes like long term neurodevelopmental outcomes and maternal side effects may not have surfaced

Hence well designed randomized double blinded studies are recommended further for improving level of evidence

\section{Acknowledgements}

We are thankful to our patients and colleagues for their contribution to the work.

\section{Conflict of Interest: None declared}

\section{Funding: No funding sources}

\section{References}

1. Tenore JL. Methods for cervical ripening and induction of labor. Am Fam Physician. 2003 May 15;67 (10):21238 .

2. Savitz D, Terry JW, Dole N, Thorp JM, Siega-Riz AM, Herring AH. Comparison of pregnancy dating by LMP, ultrasound scanning, and their combination. Am J Obstet Gynecol 2002;187:1660-6.

3. World Health Organization. WHO recommendations for induction of labour. Geneva: World Health Organization; 2011.

4. Brouwers HAA, Bruins HW, van Huis AM, de Miranda E, Ravelli ACJ, Tamminga P. Netherlands: Perinatal Registration Netherlands (PRN) 20104.

5. Johnson DP, Davis NR, Brown AJ. Risk of cesarean delivery after induction at term in nulliparous women with an unfavorable cervix. American journal of obstetrics and gynecology. 2003 Jun 30;188(6):1565-72.

6. Macer JA, Macer CL, Chan LS. Elective induction versus spontaneous labor: a retrospective study of complications and outcome. American journal of obstetrics and gynecology. 1992 Jun 30;166(6):1690-7.

7. Vrouenraets FP, Roumen FJ, Dehing CJ, van den Akker ES, Aarts MJ, Scheve EJ. Bishop score and risk of cesarean delivery after induction of labor in nulliparous women. Obstetrics \& Gynecology. 2005 Apr 1;105(4):690-7.

8. Cole RA, Howie PW, Macnaughton MC. Elective induction of labour: a randomised prospective trial. The Lancet. 1975 Apr 5;305(7910):767-70.

9. Heimstad R, Skogvoll E, Mattsson LA, Johansen OJ, EikNes SH, Salvesen KA. Induction of labor or serial antenatal fetal monitoring in postterm pregnancy: a randomized controlled trial. Obstetrics \& Gynecology. 2007 Mar 1;109(3):609-17.

10. Hermus MA, Verhoeven CJ, Mol BW, de Wolf GS, Fiedeldeij CA. Comparison of induction of labour and expectant management in post term pregnancy: a matched cohort study. J Midwifery Womens Health 2009, 54(5):351-356.

11. Sanchez-Ramos L, Olivier F, Delke I, Kaunitz AM. Labor Induction versus Expectant Management for Postterm Pregnancies: A Systematic Review with Meta-analysis. Obstetrics \& Gynecology. 2003 Jun 1;101(6):1312-8.

12. McNellis D, Medearis AL, Fowler S, Romero R, Sibai BM, Caritis SN et al.. A clinical trial of induction of labor versus expectant management in postterm pregnancy. American Journal of Obstetrics and Gynecology. 1994;170(3):716-23.

13. Haq AN, Ahsan S, Sher Z. Induction of labour in postdates pregnant women. J Coll Physicians Surg Pak. 2012 Oct 1;22:64.

14. Hannah ME. Postterm pregnancy: should all women have labour induced? A review of the literature. Fetal and Maternal Medicine Review. 1993 Feb 1;5(01):3-17.

15. Alexander JM, McIntire DD, Leveno KJ. Forty weeks and beyond: pregnancy outcomes by week of gestation. Obstetrics \& Gynecology. 2000 Aug 31;96(2):291-4. 
16. Kaimal AJ, Little SE, Odibo AO, Stamilio DM, Grobman WA, Long EF et al. Cost-effectiveness of elective induction of labor at 41 weeks in nulliparous women. American journal of obstetrics and gynecology. $2011 \mathrm{Feb}$ 28;204(2):137-e1.

17. Prysak M, Castronova FC. Elective induction versus spontaneous labor: a case-control analysis of safety and efficacy. Obstetrics \& Gynecology. 1998 Jul 1;92(1):4752.

18. Augensen KA, Bergsjø P, Eikeland T, Askvik K, Carlsen J. Randomised comparison of early versus late induction of labour in post-term pregnancy. Br Med J (Clin Res Ed). 1987 May 9;294(6581):1192-5. 